\title{
Drama e a teoria histórico-cultural: interlocuções possíveis
}

\section{Drama and the historical-cultural theory: possible interlocutions}

Diego de Medeiros Pereira ${ }^{1}$ 


\section{Resumo}

O presente texto busca propor um diálogo entre o Drama, método inglês de ensino e experimentação do teatro, difundido no Brasil pela professora Beatriz Cabral, e a teoria histórico-cultural de Lev Vygotsky (1896-1934), uma das principais referências que fundamenta as propostas curriculares voltadas à Educação brasileira. A interlocução é proposta a partir de três conceitos presentes tanto na teoria de $\mathrm{Vy}$ gotsky quanto na abordagem do Drama: contexto, interação e mediação. Intentase lançar bases para uma discussão acerca da dimensão pedagógica dessa abordagem para o ensino do teatro, enfatizando-se sua proximidade com as reflexões pedagógicas contemporâneas.

Palavras-chave: Drama; pedagogia do teatro; Lev Vygotsky; educação.

\section{Abstract}

This text tries to propose a dialogue between the British teaching and experimenting theater method called Drama, brought to Brazil by professor Beatriz Cabral, and the historical-cultural theory by Lev Vygotsky (18961934), one of the main references that grounds curriculum proposals focused on brazilian Education. The interlocution proposed is based on three concepts found both in Vygotsky's theory and in the Drama approach: context, interaction and mediation. The essay intents to set out bases for a discussion on the pedagogical dimensions of this approach concerning the teaching of Drama, with an emphasis on its proximity with the contemporary pedagogical reflections.

Keywords: Drama; theatre pedagogy; Lev Vygotsky; education.
ISSN: 1414.5731

E-ISSN: 2358.6958

1 Doutor em Teatro pelo Programa de Pós-graduação em Teatro (PPGT) UDESC. Professor Colaborador no Departamento de Artes Cênicas - UDESC e Professor de Teatro na Prefeitura Municipal de Florianópolis. diego_ccac@hotmail.com 


\section{Contexto do Drama}

O Drama teve origem em meados dos anos de 1950 a partir de um movimento realizado por professores e estudiosos ingleses que questionaram as práticas de ensino do teatro pautadas no treinamento das crianças como atores, focadas, principalmente, na montagem de espetáculos. Esse movimento ficou conhecido como "Drama na Educação" em oposição ao modelo tradicional de ensino do teatro por meio de montagens, intitulado "Drama Educação".

A professora e atriz Dorothy Heathcote (1926-2011) tornou-se a principal representante do movimento de "Drama na Educação" no sistema educacional inglês. No final dos anos de 1970, o Drama passou a ser reconhecido como uma forma de arte e praticado em países como Austrália, Inglaterra, Canadá, no norte europeu e Estados Unidos, pontua O'Toole (1992, p. 04).

Para Heathcote "[...] drama não são histórias recontadas por meio de ações. Drama significa seres humanos confrontando-se com situações que os modificam por conta do que eles devem enfrentar ao lidar com desafios" (Heathcote apud O'Neill, 1984, p. 48). Nessa perspectiva, o Drama torna-se promotor de uma construção conjunta de conhecimentos. Os participantes ao agirem, reagirem e interagirem, imersos em um contexto ficcional, apropriar-se-ão de saberes relativos à situações reais, seja de conteúdos curriculares, de temáticas de seu interesse ou de questões sociais mais amplas.

Assim, a abordagem de Heathcote, conhecida como Drama Vivencial, ao invés de buscar a dramatização de peças teatrais utilizando textos prontos, incentivava os estudantes a elaborarem conjuntamente suas próprias histórias a partir de questões do seu contexto. Em um processo que se desenvolvia etapa por etapa, os participantes tinham que tomar decisões para dar direcionamento ao Drama, evidenciando-se, dessa forma, a utilização da improvisação teatral como base para a experimentação e aprendizagem dos temas e conteúdos abordados no processo.

Vidor (2010) destaca que Heathcote reforçou o caráter educacional do Drama, ao relacioná-lo à aquisição de conhecimentos e não ao desenvolvimento de habilidades teatrais, como propunham os modelos tradicionais de trabalho com tal linguagem, "[...] sem desconsiderar seu valor artístico e sua origem no teatro" (Vidor, 2010, p. 28), buscando o fazer artístico como um caminho para a construção de saberes diversos.

Outros autores contribuíram para a difusão do Drama como abordagem para ensino e experimentação da linguagem teatral, dentre os principais, pode-se citar o inglês Gavin Bolton, contemporâneo e parceiro de Heathcote, a irlandesa Cecily O'Neil, que criou uma variante conhecida como Process Drama (Drama Processo), o australiano John O'Toole, precursor do Drama na Austrália e o inglês Jonathan Neelands, que em seus trabalhos busca enfatizar a estreita relação entre Drama e Teatro.

\footnotetext{
2 "Drama is not stories retold in action. Drama is human beings confronted by situations which change them because of what they must face in dealing with those challenges" (tradução nossa).
} 
No Brasil, o Drama foi introduzido por Beatriz Cabral depois de seu doutorado na University of Central England (1990-1994) em Birmingham (Reino Unido) onde participou de processos de Drama conduzidos por Heathcote. Seu livro Drama como método de ensino (2006) é a principal referência sobre a apropriação desse método no nosso país. Nessa obra, e em dezenas de trabalhos publicados sobre Drama deste então, Cabral tem abordado diferentes aspectos desse método, desde sua estrutura, proposta metodológica, construção histórica, à sua base filosófica. Para Cabral,

[...] a atividade dramática está centrada na interação com contexto e circunstâncias diversas, em que os participantes assumem papéis e vivem personagens como se fizessem parte daquele contexto naquelas circunstâncias. Para o participante isto significa 'assumir o controle da situação', ser o responsável pelos fatos ocorridos. Envolvimento emocional e responsabilidade pelo desenvolvimento da atividade são características essenciais do drama - o aluno é o autor de sua criação (Cabral, 2006, p. 33).

Enquanto fora do Brasil o Drama é trabalhado tanto por professores de teatro quanto por profissionais de diversas áreas, sendo, em muitos casos, utilizado como um meio para aquisição de conhecimentos das disciplinas do currículo, no Brasil o Drama foi introduzido como um método para a experimentação teatral que contribuísse com a apropriação, pelos participantes, de estruturas e conceitos teatrais. Esse contexto se deu devido ao fato de Cabral atuar, naquele momento, em um curso de Licenciatura em Teatro e, nesse sentido, suas pesquisas e experimentos buscaram aproximar o Drama do ensino da linguagem teatral.

Desgranges (2006) assinala que esse método não foi amplamente difundido no contexto pedagógico brasileiro por conta da existência de diferentes compreensões acerca dos seus objetivos e procedimentos, dificultando sua difusão de forma estruturada.

\section{As proposições vygotskianas}

A teoria histórico-cultural (também conhecida como sócio histórica ou sócio interacionista) teve início com as obras de Lev Vygotsky desenvolvidas em meio à revolução socialista russa de 1917 e à ditadura socialista da União Soviética. O objetivo central dos seus estudos, segundo Rego era "[...] caracterizar os aspectos tipicamente humanos do comportamento e elaborar hipóteses de como essas características se formaram ao longo da história humana e de como se desenvolvem durante a vida de um indivíduo" (2013, p. 38). Essa abordagem, portanto, definia o sujeito como um ser construído a partir da apropriação e reelaboração de ações, conceitos e signos historicamente e socialmente construídos pelos membros mais antigos do seu grupo e revistos frente às novas configurações sociais, desafios e descobertas geradas com o passar dos anos.

Divergindo das concepções inatista, segundo a qual as capacidades humanas encontrar-se-iam prontas desde o nascimento, necessitando apenas do amadurecimento natural, e ambientalista, que atribuía ao meio a responsabilidade pela construção do ser, Vygotsky defendia que ambos, organismo e meio, eram reciprocamente 
influentes no processo de construção do psiquismo humano.

Nesse sentido, o desenvolvimento humano necessita ser compreendido como algo orgânico, em permanente construção e ligado a um determinado contexto. A tentativa da psicologia, sobretudo das teorias de Piaget ${ }^{3}$, de definir características e leis universalmente válidas para o desenvolvimento infantil foi objeto de crítica de Vygotsky.

Esse autor diferencia as funções psicológicas elementares, comuns a homens e animais (tais como: atenção e memória involuntária) das funções exclusivamente humanas, denominadas funções psicológicas superiores (tais como: controle consciente do comportamento, atenção e memória voluntária, memorização ativa, pensamento abstrato, raciocínio dedutivo, capacidade de planejamento).

As funções superiores, para Vygotsky, tem origem cultural e não biológica, pois, segundo esse autor, elas se originam a partir das relações estabelecidas entre os indivíduos e desses com o meio, através da internalização de comportamentos, conceitos e signos. Como aponta Vygotsky: "a internalização das atividades socialmente enraizadas e historicamente desenvolvidas constitui o aspecto característico da psicologia humana; é a base do salto quantitativo da psicologia animal para psicologia humana" (1996, p. 58). O sujeito é, portanto, um ser histórico.

Como o ser é inserido na cultura pelos membros do seu grupo social, estabelecer relações com parceiros mais experientes no processo de construção de conhecimentos passa a ser fundamental. Por conta dessa prerrogativa, Vygotsky atribuiu à escola uma grande importância, uma vez que será no espaço escolar que a criança passará boa parte de sua infância e adolescência, estabelecendo relações com seus pares, apropriando-se dos conhecimentos historicamente acumulados e constituindo-se como sujeito - tanto na sua individualidade quanto nos aspectos que a fazem pertencer a um determinado grupo.

No espaço educacional a apropriação das linguagens oral e escrita permitirá a criação de oportunidades de intercâmbio de informações que levará o educando à assimilação de novos conhecimentos. Os brinquedos, livros, imagens, materiais escolares, entre outros, funcionarão como instrumentos facilitadores dos processos de desenvolvimento da criança. Na perspectiva histórico-cultural, portanto, o desenvolvimento e a aprendizagem não ocorrem a partir de um acúmulo entre fatores biológicos e fatores sociais, mas através de uma interação dialética desses.

As ideias de Vygotsky tem se difundido tanto nos meios acadêmicos quanto nas diversas redes de ensino do nosso país. Rego aponta que o pensamento desse autor, "[...] sugere um novo paradigma que possibilita um modo diferente de olhar a escola, o conhecimento, a criança, o professor e até a sociedade" (2013, p. 124). Nesse sentido, estabelecer relações entre sua teoria e o ensino do teatro parece fundamental para que se possa vislumbrar novas perspectivas para a prática

\footnotetext{
${ }^{3}$ Jean Piaget (1896-1980) - epistemólogo suíço, fundador da Epistemologia Genética, teoria do conhecimento com base no estudo da gênese psicológica do pensamento humano.
} 
pedagógico-teatral nas escolas brasileiras. Buscar-se-á, portanto, nas reflexões que seguem, relacionar conceitos e pressupostos da teoria vygotskiana com as convenções e estratégias do Drama, a fim de aproximar e tencionar os campos da Psicologia, Pedagogia e Teatro.

\section{O contexto sociocultural}

Para Vygotsky a psicologia tradicional estudava a criança e o desenvolvimento de suas funções psíquicas desconsiderando o meio social e cultural em que ela estava imersa, assim como as formas de pensamento predominantes nesse meio. Sua teoria, ao contrário, não separa os indivíduos da situação cultural em que se desenvolvem.

As fases do desenvolvimento infantil apontadas por Vygotsky e seus colaboradores, portanto, dependem das condições concretas nas quais ocorre a evolução da criança. As condições socioculturais exercem influência tanto sobre o conteúdo concreto de um estágio individual do desenvolvimento como sobre o curso total do processo. Os limites de idade de cada estágio também dependem das condições históricas, logo, esses limites se alteram com a mudança das condições socioculturais.

A Pedagogia se apropriou desses pressupostos para conceber propostas de ação que percebessem e considerassem o contexto sócio cultural das crianças envolvidas em um processo de ensino/aprendizagem. Cada criança chega à creche/ escola com uma bagagem cultural singular e compreende-se como fundamental que o professor leve esse fator em consideração pra que estabeleça um processo efetivo de construção de saberes. No respeito à heterogeneidade do grupo, na busca por ampliar seus repertórios partindo dos seus interesses, incitando a interação das diferenças, a ação pedagógica parece se desenvolver de forma dialógica e comprometida com os sujeitos.

Nesse contexto, é possível perceber a proximidade do Drama com tal pressuposto vygotskiano. Ao convencionar que um processo dramático necessita partir do contexto real dos participantes para depois se desdobrar em um contexto ficcional, o Drama busca abarcar as diferenças e respeitar as especificidades socioculturais. Isso não significa limitar os estudantes aos seus objetos de interesse e aquilo que conhecem, mas estabelecer conexões entre conhecimentos existentes e aqueles que podem ser construídos através de uma experimentação teatral, ampliando o horizonte de experiências e referências dos participantes.

Quanto maior ressonância tiver o contexto ficcional no contexto real do grupo, maior será a probabilidade de que ele imerja na situação proposta. Quanto mais próximas estiverem as estratégias utilizadas pelo professor das especificidades apresentadas pelos participantes (faixa etária, interesses, curiosidades, desejos) maiores serão as apropriações do material oferecido pelo condutor. Um diálogo efetivo entre a proposta dramática e o contexto dos educandos, portanto, faz-se necessário para que o Drama seja relevante para o grupo e o instigue a se engajar na construção da narrativa.

Smolka, ao tratar da teoria de Vygotsky, afirma que: 
O desenvolvimento da criança, encontra-se [...] intrinsecamente relacionado à apropriação da cultura. Essa apropriação implica uma participação ativa da criança na cultura, tornando próprios dela mesma os modos sociais de perceber, sentir, falar, pensar e se relacionar com os outros (Smolka, 2009, p. 08).

Assim como a cultura existente em determinado contexto não é algo acabado e imutável, sendo construída e reconstruída pelas condições do meio e pelas relações estabelecidas pelos membros de um determinado grupo, o processo de Drama também não existe a priori, ele se constrói na intervenção direta dos participantes que fornecem materiais e se apropriam daqueles oferecidos, construindo e desconstruindo os estímulos trazidos pelo condutor do processo.

Dialogando com Rego que afirma: "[...] o ser humano não só é um produto de seu contexto social, mas também um agente ativo na criação deste contexto" (2013, p. 49), percebe-se que o Drama se configura como um encaminhamento metodológico que pode contribuir com a ampliação da capacidade comunicativa dos estudantes. Ao fornecer-lhes materiais, ao desafiá-los, ao colocá-los em situações diferentes do cotidiano, ao questionar suas respostas, ao incentivar a construção de saberes e alteração de suas percepções, O Drama pode auxiliar na modificação de suas ações no meio cultural em que se encontram, tornando a linguagem teatral uma forma de expressão apropriada pelos estudantes.

\section{O papel das interações}

A teoria histórico-cultural aponta que há uma ação recíproca entre o aparato biológico - hereditariamente herdado - e o meio sociocultural no qual o ser está imerso; nas palavras de Vygotsky:

[...] de um lado, os processos elementares, que são de origem biológica; de outro, as funções psicológicas superiores, de origem sociocultural. A história do comportamento da criança nasce do entrelaçamento dessas duas linhas (Vygotsky, 1996, p. 52).

Nesse sentido, há uma unidade entre os processos de aprendizagem e os de desenvolvimento. O aprendizado escolar, por exemplo, produz novas estruturas de pensamento e exige que processos internos sejam elaborados a fim de que novos conhecimentos sejam internalizados, portanto, para que o aprendizado ocorra é necessário o desenvolvimento de novas estruturas mentais. Como Vygotsky afirma: "[...] o aprendizado é um aspecto necessário e universal do processo de desenvolvimento das funções psicológicas culturalmente organizadas e especificamente humanas" (1996, p. 103), ou seja, o processo de desenvolvimento progride em função da aprendizagem.

A aprendizagem, entretanto, não se dá de forma autônoma, ela ocorre a partir das relações que o educando estabelece com outras pessoas (parceiros mais experientes). 
$\mathrm{Na}$ interação com o outro o sujeito é capaz de movimentar processos de desenvolvimento que, sem ajuda, seriam impossíveis de ocorrer.

Na teoria vygotskiana a interação social tem um papel central como ação promotora de processos de aprendizagem e desenvolvimento. Essas interações se dão, primeiramente, com os adultos (geralmente os pais) que procuram iniciar a criança na sua cultura e mediar as relações dela com os objetos, instrumentos, códigos e signos do mundo. Num segundo momento, as interações serão estabelecidas com os novos pares que a criança encontrará pelo caminho - crianças mais experientes, professores, familiares. Nesse processo de incorporação cultural, o estudante desenvolve funções psicológicas mais complexas, internalizando-as a partir da prática social.

A proximidade da estrutura do Drama com a teoria vygotskiana dá-se, justamente, ao propor que o processo de construção do conhecimento teatral se dê através das interações estabelecidas no ambiente ficcional. Ao participarem de uma atividade dramática os participantes utilizam de seus conhecimentos e se apropriam das respostas de seus pares, ampliando os saberes prévios. Quando o professor lança um questionamento ou um desafio, ele pode perceber em que grau se encontra a apropriação de estruturas teatrais pelo seu grupo, quais conhecimentos os participantes possuem e, dessa forma, mediar a aprendizagem e torná-la instigante e significativa.

Como Chalmers aponta,

[...] o Drama é, essencialmente, uma atividade social. Quando as pessoas atuam, cantam, dançam ou performatizam de qualquer forma, elas raramente o fazem sozinhas, são geralmente membros de um grupo ou equipe que trabalham em conjunto para criar uma experiência coletiva ${ }^{4}$ (Chalmers, 2010, p. 76).

O Drama necessita que os participantes se apropriem da situação criada e, a partir das interações, criem respostas para o encaminhamento da narrativa, apropriando-se, dessa forma, das estruturas da linguagem teatral. Na relação estabelecida com o professor (parceiro mais experiente), e com os outros participantes do processo, os estudantes terão a oportunidade de ampliarem suas formas de comunicação e expressão através do uso consciente do teatro como linguagem.

O Drama não propõe a criação de um produto artístico, a experiência dramática coletiva será construída através da imersão do grupo no processo e das relações estabelecidas dentro desse. A detenção de códigos e estruturas teatrais dar-se-á mediante a interação com os estímulos oferecidos pelo professor e a observação, de dentro do processo, tanto de sua performance quanto das de seus colegas.

\section{A importância da mediação}

Oliveira, ao citar as teorias de Vygotsky, aponta que: "a mediação em termos

\footnotetext{
4 "Drama is essentially a sociable activity. When people act, sing, dance or perform in any way, they seldom do so alone, but are usually members of a grou por team who work together to create a whole experience" (tradução nossa).
} 
genéricos é o processo de intervenção de um elemento intermediário numa relação; a relação deixa, então, de ser direta e passa a ser mediada por esse elemento" (1997, p. 26), que pode ser um instrumento (objetos do cotidiano, ferramentas, máquinas, brinquedos), um signo (fenômenos, gestos, figuras, sons, entre outros, que representam algo diferente de si mesmo) ou uma outra pessoa.

No caso da escola, a mediação entre educando e conhecimento é realizada pelo professor que, para efetuar esse processo mediático, necessita considerar o indivíduo historicamente e socialmente localizado. Cabe ao educador fornecer instrumentos para que a criança amplie suas ações, criando e recriando de forma própria sua maneira de agir, sentir e ver o mundo. Nesse contexto, o papel do professor ganha destaque como parceiro mais experiente, mediador na construção de saberes e incitador de oportunidades de interação.

No que diz respeito à apropriação da linguagem teatral por meio do Drama, o professor condutor assume, constantemente, a função de mediador, o que exige dele observar quais conhecimentos os estudantes possuem, como eles respondem às suas intervenções e quais outros desafios podem ser postos para que o processo se desenrole, os participantes se apropriem do conhecimento teatral e criem os rumos da narrativa. Essa mediação ocorre tanto dentro do contexto ficcional, quanto no planejamento do episódio 5 .

As estratégias professor personagem e professor no papel, por exemplo, buscam justamente colocar o professor em um lugar mediador dentro da ficção. Como personagem inserido no contexto ficcional, parceiro dos estudantes na experimentação dramática, o professor deixa de ser um instrutor e intervém diretamente na construção da narrativa.

Essa estratégia do Drama, originada no trabalho de Heathcote e que ganhou novos contornos (principalmente artísticos) quando utilizada por estudantes e professores de Teatro, mostra-se fundamental no trabalho com educandos que não possuem experiência como espectadores. A transformação do professor em personagem na frente do grupo é uma estratégia que favorece a compreensão do espaço ficcional do jogo além de incentivar os participantes a experimentarem os papéis propostos pelo Drama.

A apropriação do teatro como experiência em processo e não como produto artístico altera a relação do estudante com a arte teatral e essa alteração está associada diretamente à maneira como o professor promoverá esse contato, como realizará a mediação. Como afirma Chalmers:

[...] se você se levantar e se lançar no primeiro acontecimento da história com entusiasmo, todos deverão se sentir inspirados a segui-lo! Narrar

\footnotetext{
5 Cada nova proposição, situação criada ou atividade realizada em um processo é considerada um episódio do Drama. Podemos pensar os episódios como unidades cênicas que compõem o processo. Observando as palavras de Desgranges, "os episódios são os fragmentos e/ou eventos que compõem a estrutura narrativa. 0 processo desenvolve-se através de episódios que vão pouco a pouco construindo a narrativa teatral" (2006, p. 126).
} 
a história de forma apropriada desdobrando-a em ações e expressões, encorajará todos a copiar o que você está fazendo, mas não necessariamente imitando-o exatamente (Chalmers, 2010, p. 79).

Ao se colocar como mediador de um processo de Drama, acredita-se necessário que o professor se questione quanto ao seu repertório cultural, suas experiências com a arte, suas visões de mundo, a maneira como lida com as diferenças, os preconceitos que possui. Como mediador, ele será o promotor das ações que desencadearão no desenvolvimento de seus educandos. Esses, pelo menos em um primeiro momento, irão se apropriar dos materiais, conceitos e conteúdos fornecidos por seu professor. É importante refletir sobre o que se está oferecendo.

Nesse sentido, a ação mediadora pressupõe intencionalidade, o que exige planejamento, avaliação, registro do processo, considerando as diferenças existentes no grupo. Uma atividade livre ou um jogo aleatório, pouco contribuem para que o educando desenvolva algo além do que conhece. Nessas atividades ele tenderá a utilizar o repertório que possui e, se esse for escasso, suas criações também serão escassas e limitadas. É necessário que o professor se disponha a traçar um diagnóstico do seu grupo e, a partir daí, conduza o processo de ensino/aprendizagem possibilitando a experimentação de novas atividades e a aquisição de novos conhecimentos.

A condução de um processo de Drama exigirá do mediador uma postura questionadora. Essa atitude necessita permear todo o processo; inquerir os participantes sobre suas opiniões, sobre experiências anteriores, sobre como podem resolver um problema, quais as possibilidades que eles imaginam para desvendar um mistério, o que eles pensam e sentem a cada nova tarefa ou atividade. O mediador necessita perceber e avaliar tanto as respostas verbais como as não verbais (as ações realizadas pelos estudantes nas situações, as relações que estabelecem com os outros participantes, a maneira como interagem, suas criações corporais, seu engajamento físico e emocional, etc.).

Ao coletar e analisar as respostas do grupo o professor fornecerá outros materiais que darão encaminhamento ao processo. Incentivará à reflexão dos participantes avaliando com eles os acontecimentos. Buscará quebrar com julgamentos de valor de certo ou errado, construindo conhecimentos sobre os significados das suas ações e reações. Checará os fatos que foram marcantes e a repercussão de alguma estratégia utilizada ou de algum acontecimento ocorrido. Direcionará o foco de atenção dos participantes para um ponto que seja importante dentro do seu planejamento. Estabelecerá novas situações ampliando, dessa forma, as discussões sobre possiveis dilemas. Perceberá as relações que eles estabelecem entre as experiências realizadas no contexto dramático e no contexto real.

Como aponta Cabral,

\footnotetext{
6 "If you stand up and launch into the first happening in the story with enthusiasm, everybody should feel inspired to follow you! Narrate the storyline as appropriate as your actions and expressions unfold, encouraging everybody to copy what you are doing, but not necessarily to imitate you exactly" (tradução nossa).
} 
[...] o sucesso ou fracasso do drama como método de ensino ou aprendizagem reflete a habilidade do professor para coordenar as interações dos alunos em diferentes níveis a fim de equilibrar fazer e apreciar e de introduzir situações, informações e/ou desafios na hora certa de acordo com os diferentes papéis e ações (Cabral, 2006, p. 31).

É de fundamental importância, desse modo, o papel do professor como condutor no processo de experimentação e construção da linguagem teatral pelo educando. Do contato inicial, mediado por esse profissional, dependerá, em grande parte, a relação futura desse sujeito com o teatro.

\section{Algumas considerações}

As diretrizes curriculares nacionais e locais apontam para a leitura do contexto dos estudantes como "ponto de partida" para a efetivação de toda e qualquer ação pedagógica. A construção de conhecimentos a partir da interação com sujeitos mais experientes no meio social e cultural é a base para pensarmos a conexão entre os conhecimentos historicamente acumulados e a realidade concreta dos educandos. A mediação do professor é o fator primordial no processo de ensino/aprendizagem; ao observar o contexto do grupo e incitar a troca de experiências, ele incentiva a aquisição de novos saberes.

Esses três conceitos são a base para a compreensão da teoria histórico cultural de Lev Vygotsky que tem servido de referência para as citadas diretrizes. A leitura do contexto sociocultural, a promoção das interações e a mediação, são ações integradas num processo pedagógico que considere o educando como um ser construtor de conhecimentos.

Como exposto ao longo deste texto, o Drama, do mesmo modo, pauta-se nesses conceitos/ações para propor a construção da uma experiência teatral que coloque o participante de um processo como centro da criação. Seus saberes iniciais são observados pelo professor que, como mediador do processo, vestindo ou não um personagem, conduzirá os participantes a novas descobertas e à apropriação da linguagem teatral. A interação com outros membros do grupo e com os materiais que darão suporte à experiência promoverá a aquisição de novos saberes e pontos de vista.

O contexto sociocultural com o qual se depara na escola, em geral, aponta para a distância entre os educandos e os espaços de arte (teatros, cinemas, museus, shows, entre outros) assim como para a distância com as linguagens da arte e a falta de percepção de que podem se utilizar de tais linguagens como forma de expressão. Partir do contexto do grupo, das formas dramáticas que se encontram no seu cotidiano, buscando ampliar seu olhar sobre a arte teatral, mediando, sem preconceitos ou rotulações, essa construção, parece fundamental para que se possa vislumbrar a inserção dos estudantes nos espaços artístico-culturais, como espectadores, e, por que não, como criadores.

Promover, desse modo, um diálogo entre o Drama e a teoria histórico-cultural é uma maneira de alargar a visão dos educadores teatrais acerca das possibilidades des- 
sa abordagem para o ensino do teatro, além de possibilitar uma reflexão acerca de como o Drama abarca, dentro de sua estrutura, discussões contemporâneas sobre a escola: diagnosticar, mediar e interagir, numa interlocução com a realidade.

\section{Referências}

CABRAL, Beatriz. Drama como método de ensino. São Paulo: Editora Hucitec, 2006.

CHALMERS, Debbie. Drama 3-5: a practical guide to teaching drama to children in the foundation stage. Londres: Routledge, 2010.

DESGRANGES, Flávio. Pedagogia do Teatro: provocação e dialogismo. São Paulo: Hucitec, 2006.

OLIVEIRA, Marta de. Vygotsky: aprendizado e desenvolvimento um processo sócio -histórico. São Paulo: Scipione, 1997.

O'NEILL, Cecily. Dorothy Heathcote: Collected Writings on Education and Drama. Londres: Hutchinson, 1984.

O'TOOLE, John. The Process of Drama: negotiating art and meaning. Londres: Routledge, 1992.

REGO, Teresa Cristina. Vygotsky: uma perspectiva histórico-cultural da educação. Petrópolis, RJ: Vozes, 2013.

SMOLKA, Ana Luiza. Imaginação e criação na infância [prefácio]. São Paulo: Ática, p. 07-10, 2009.

VIDOR, Heloise. Drama e Teatralidade: o ensino do teatro na escolar. Porto Alegre: Editora Mediação, 2010.

VYGOTSKY, Lev. A formação social da mente. Rio de Janeiro: Martins Fontes, 1996. 